\title{
TRENDS IN THE DEVELOPMENT OF SOMATIC PARAMETERS AND MOTION PERFORMANCE IN ROMANY CHILDREN OF PRIMARY SCHOOL AGE
}

\author{
${ }^{a}$ RUDOLF HORVÁTH, ${ }^{b}$ PETER PETRIKÁN, ${ }^{c}$ INGRID \\ RUŽBARSKÁ \\ Pedagogical Faculty, Prě̌ov University in Prě̌ov, ul. 17 \\ novembra 15, 08001 Prešov Slovakia \\ email: ${ }^{a}$ rudolf.horvath@unipo.sk, ${ }^{b}$ \\ peter.petrikan.p1@gmail.com, ${ }^{c}$ ingrid.ruzbarska@unipo.sk
}

This research was implemented within the VEGA 1/0122/19 project Somatic and motor characteristics of primary school children and their development trends with the focus on marginalized Romany communities.

Abstract: The paper presents the results of research covering 596 Romany children of perameters and the mirls. In order to determine the trends in the development of these children, the results were compared col the chister living in significance of the differences between the results obtained in 2000 and 2019. We nalyzed the somatic parameters and motion performance of Romany children attending primary school in terms of improved or worse results during the period of 19 years. We calculated the basic statistical values and tested the hypotheses by Student ttest. The results are summarized in tables and diagrams. It was found out that the somatic parameters of Romany boys and girls of all age categories have significantly improved. The motion performance has also improved in a statistically significant manner, however, this finding does not hold for all test items not for all age categories.

Keywords: Somatic parameters, motion performance, primary school age, Eurofit test, Romany children

\section{Introduction}

The questions of life conditions, social status, health and education of a part of the Romany population in Slovakia have been presented as a serious problem on number of occasions. It has been pointed out that these problems primarily occur in ethnically homogeneous communities defined in the governmental documents as marginalized Romany communities. Academics have pointed out many times that the reason for the effort to tackle and solve these problems (usually of low success rate) is an insufficient knowledge of internal and external causes of these problems. No doubt, these problems are not monothematic; on the contrary, they are highly complex and interrelated (or, mutually conditioned). The Romany population in Slovakia amounts to about 450000 people. They mostly live in East Slovakia. While children in the majority population represent $12 \%$, in the Romany community it is $46 \%$.. Our project is aimed to contribute to and update the available empirical and scientific knowledge of the fundamental socio-bio-physiological characteristics and differences in the development of Romany children who attend primary schools. These issues bear on a range of both contemporary and future problems of marginalized Romany communities (we are referring to the interconnection between the health condition, the socialeconomic situation, success at school, the ability to find a job, etc.). The project objective consists in the identification of the somatic development and motor abilities in primary school children coming from marginalized Romany communities by means of anthropometric methods and by application of the standardized Eurofit test. The new data will be compared to those obtained 19 years ago and presented in Horváth (2001) in order to determine the development trend of motor abilities. No such research has yet been implemented in Slovakia.

\section{Methods}

\subsection{Data acquisition methods}

The research data were collected at East Slovakian primary schools from January to June 2019. We measured somatic parameters, weight (TH) and height (TV) in 7- to 10-year-old Romany children. Based on these data we calculated the BMI value:
The motion performance was determined by means of the EUROFIT test according to Moravec et al. (1994,1996). We tested 596 Romany pupils at primary schools, including 286 boys and 310 girls.

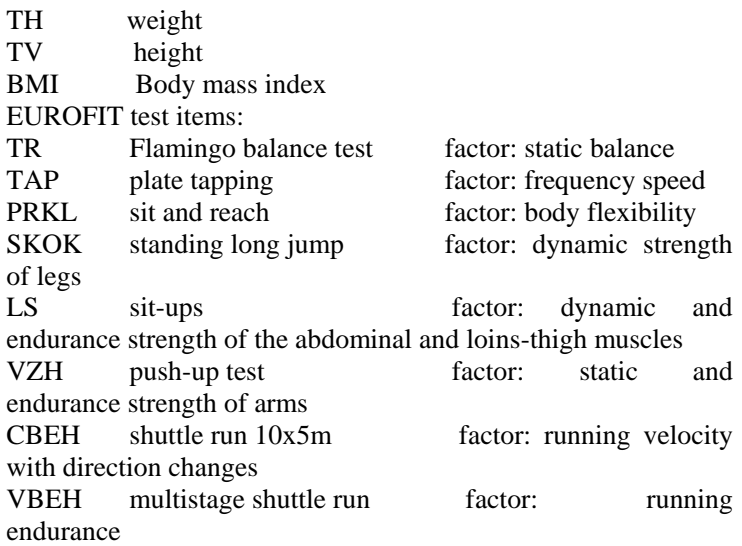

\subsection{Research hypotheses}

H0 -1: It is hypothesized that there will be no statistically significant difference between the results of Romany children in the 2000 research and the results in the 2019 research in terms of individual somatic parameters.

H1 -1: It is hypothesized that there will be a statistically significant difference between the results of Romany children in the 2000 research and the results in the 2019 research in terms of individual somatic parameters.

HO -2: It is hypothesized that there will be no statistically significant difference between the results of Romany children in the 2000 research and the results in the 2019 research in terms of individual motion performance tests.

H1 -2: It is hypothesized that there will be a statistically significant difference between the results of Romany children in the 2000 research and the results in the 2019 research in terms of individual motion performance tests

H0-3: It is hypothesized that the somatic parameter results of Romany children participating in the 2019 research will be better than those of Romany children who took part in the 2000 research.

H1-3: It is hypothesized that the somatic parameter results of Romany children participating in the 2019 research will not be better than those of Romany children who took part in the 2000 research.

H0-4: It is hypothesized that the motion performance results of Romany children participating in the 2019 research will be better than those of Romany children who took part in the 2000 research.

H1-4: It is hypothesized that the motion performance results of Romany children participating in the 2019 research will not be better than those of Romany children who took part in the 2000 research

\subsection{Data processing}

These hypotheses will be verified by means of statistical methods. Hypotheses $\mathrm{H} 01$ and $\mathrm{H} 0-2$ will be confirmed or rejected by Student's one sample t-test. A correct use of this test requires an analysis of the test cohort normality. This is tested by Shapiro Wilk test. This test has confirmed the cohort normality and thus justified the use of the parametric Student's t-test. The " $t$ " value is calculated as follows:

$$
t=\left(\frac{x_{2000}-x_{2019}}{s}\right) \sqrt{n}
$$

where 
$\mathrm{X}_{2000}$ - arithmetic average of the research values in Horváth (2001)

$\mathrm{X}_{2019}$ - arithmetic average of the research values in 2019

$\mathrm{s}$-standard deviation in 2019

$\mathrm{n}$ - number of probands in 2019

The calculated value $t$ was compared at the expected significance level of $\alpha=0,05$ to the table value of Student's distribution at n-1 degrees of freedom $t_{\text {krit }}$. If $t>t_{\text {krit }}$ the null hypothesis $\mathrm{H} 0$ is rejected and the alternative $\mathrm{H} 1$ hypothesis is accepted.

\section{$2 \quad$ Results and discussion}

2.1 Somatic parameters

The obtained somatic parameter values were used to calculate the BMI - the Body mass index - and the basic statistical values - the arithmetic average and the standard deviation. Student's one sample t-test was applied to all the values and age categories in order to confirm/reject the H01 hypothesis saying that there is no statistically significant difference between the somatic parameters in Romany children in Horváth (2001) and the 2019 research. The data are presented in Table 1 and Table 2.

Tab. 1: Somatic parameters of 7- and 8-year-old Romany boys and girls

\begin{tabular}{|c|c|c|c|c|c|c|c|c|c|c|c|c|c|c|}
\hline \multicolumn{3}{|c|}{ age } & \multicolumn{6}{|c|}{7} & \multicolumn{6}{|c|}{8} \\
\hline & & & $\mathrm{n}$ & $\mathrm{x}$ & $\mathrm{s}$ & $\mathrm{t}$ & tkrit & $t$ test & $\mathrm{n}$ & $\mathrm{x}$ & $\mathrm{s}$ & $\mathrm{t}$ & tkrit & $\mathrm{t}$ test \\
\hline \multirow{4}{*}{ TV } & \multirow{2}{*}{ boys } & 2000 & 135 & 115.59 & 06.3 & \multirow{2}{*}{8.53} & \multirow{2}{*}{1.993} & & 142 & 121.09 & 5.31 & \multirow{2}{*}{7.69} & \multirow{2}{*}{1,99} & \\
\hline & & 2019 & 72 & 122.35 & 6.72 & & & $* *$ & 74 & 127.22 & 06.8 & & & $* *$ \\
\hline & \multirow{2}{*}{ girls } & 2000 & 136 & 114.84 & 6.71 & \multirow{2}{*}{8.91} & \multirow{2}{*}{1,99} & & 132 & 120.47 & 06.4 & \multirow{2}{*}{7.79} & \multirow{2}{*}{1.987} & \\
\hline & & 2019 & 74 & 120.12 & 05.9 & & & $* *$ & 87 & 125.86 & 6.45 & & & $* *$ \\
\hline \multirow{4}{*}{$\mathrm{TH}$} & \multirow{2}{*}{ boys } & 2000 & 135 & 20.92 & 2.39 & \multirow{2}{*}{7.69} & \multirow{2}{*}{1.993} & & 142 & 23.18 & 2.91 & \multirow{2}{*}{7.26} & \multirow{2}{*}{1.993} & \\
\hline & & 2019 & 72 & 24.45 & 03.8 & & & $* *$ & 74 & 28.68 & 6.86 & & & $* *$ \\
\hline & \multirow{2}{*}{ girls } & 2000 & 136 & 20.78 & 03.1 & \multirow{2}{*}{5.52} & \multirow{2}{*}{1.993} & & 132 & 22.64 & 3.00 & \multirow{2}{*}{8.74} & \multirow{2}{*}{1.95} & \\
\hline & & 2019 & 74 & 22.1 & 2.89 & & & $* *$ & 87 & 26.75 & 4.38 & & & $* *$ \\
\hline \multirow{4}{*}{ BMI } & \multirow{2}{*}{ boys } & 2000 & 135 & 15.66 & 1.51 & \multirow{2}{*}{8.49} & \multirow{2}{*}{1.993} & & 142 & 15.81 & 1.56 & \multirow{2}{*}{5.25} & \multirow{2}{*}{1.993} & \\
\hline & & 2019 & 72 & 16.29 & 01.8 & & & $* *$ & 74 & 17.62 & 2.94 & & & $* *$ \\
\hline & \multirow{2}{*}{ girls } & 2000 & 136 & 15.66 & 1.69 & \multirow{2}{*}{2.84} & \multirow{2}{*}{1.992} & & 132 & 15.75 & 1.27 & \multirow{2}{*}{5.46} & & \\
\hline & & 2019 & 74 & 17.44 & 2.56 & & & $* *$ & 87 & 18.36 & 1.56 & & & $* *$ \\
\hline
\end{tabular}

Tab. 2: Somatic parameters of 8-, 9- and 10-year-old Romany boys and girls

\begin{tabular}{|c|c|c|c|c|c|c|c|c|c|c|c|c|c|}
\hline \multicolumn{2}{|c|}{ age } & \multicolumn{6}{|c|}{9} & \multicolumn{6}{|c|}{10} \\
\hline & & $\mathrm{n}$ & $\mathrm{x}$ & $\mathrm{s}$ & $\mathrm{t}$ & tkrit & $\mathrm{t}$ test & $\mathrm{n}$ & $\mathrm{x}$ & $\mathrm{s}$ & $\mathrm{t}$ & tkrit & $\mathrm{t}$ test \\
\hline \multirow{4}{*}{ TV } & \multirow{2}{*}{ boys } & 141 & 125.43 & 05.8 & \multirow{2}{*}{5.50} & \multirow{2}{*}{1.994} & & 132 & 130.96 & 01.6 & \multirow{2}{*}{6.83} & \multirow{2}{*}{1.94} & \\
\hline & & 72 & 130.14 & 7.21 & & & $* *$ & 72 & 137.06 & 7.52 & & & $* *$ \\
\hline & \multirow{2}{*}{ girls } & 133 & 124.5 & 6.56 & \multirow{2}{*}{7.87} & \multirow{2}{*}{1.993} & & 141 & 130.23 & 07.3 & \multirow{2}{*}{10.33} & \multirow{2}{*}{1.990} & \\
\hline & & 74 & 130.57 & 6.58 & & & $* *$ & 77 & 139.85 & 08.4 & & & $* *$ \\
\hline \multirow{4}{*}{$\mathrm{TH}$} & \multirow{2}{*}{ boys } & 141 & 24.94 & 4.53 & \multirow{2}{*}{7.94} & \multirow{2}{*}{1.994} & & 132 & 27.4 & 04.7 & \multirow{2}{*}{7.34} & \multirow{2}{*}{1.994} & \\
\hline & & 72 & 32.04 & 7.54 & & & $* *$ & 72 & 35.93 & 10.2 & & & $* *$ \\
\hline & \multirow{2}{*}{ girls } & 133 & 24.31 & 3.56 & \multirow{2}{*}{7.67} & \multirow{2}{*}{1.993} & & 141 & 27.4 & 04.8 & \multirow{2}{*}{9.82} & \multirow{2}{*}{1.99} & \\
\hline & & 74 & 29.95 & 6.24 & & & $* *$ & 77 & 36.25 & 8.17 & & & $* *$ \\
\hline \multirow{4}{*}{ BMI } & \multirow{2}{*}{ boys } & 141 & 15.78 & 02.2 & \multirow{2}{*}{7.167} & \multirow{2}{*}{1.994} & & 132 & 15.85 & 1.94 & \multirow{2}{*}{6.76} & \multirow{2}{*}{1.954} & \\
\hline & & 72 & 18.75 & 3.55 & & & $* *$ & 72 & 18.87 & 3.77 & & & $* *$ \\
\hline & \multirow{2}{*}{ girls } & 133 & 15.66 & 1.85 & \multirow{2}{*}{5.41} & \multirow{2}{*}{1.993} & & 141 & 15.85 & 1.82 & \multirow{2}{*}{9.15} & & \\
\hline & & 74 & 17.44 & 06.7 & & & $* *$ & 77 & 18.37 & 02.4 & & & $* *$ \\
\hline
\end{tabular}

n number of the tested children

$\mathrm{x}$ arithmetic average of the measured values

$\mathrm{s} \quad$ standard deviation of the measured values

calculated t-test value

tkrit Student's t distribution table value

t test $* *$ statistical significance of the values at the level of 0.05
Tables 1 and 2 suggest that $\mathrm{t}>$ tkrit holds for all age categories of boys and girls and therefore the differences between the 2000 and the 2019 cohorts at the level of 0.05 are statistically significant. This rejects the $\mathrm{H} 01$ null hypothesis. The H1 hypothesis has been confirmed. It means that there are statistically significant differences between the two cohorts at the expected significance level of $\alpha=0,05$

The differences are illustrated in Graph 1. 
TV

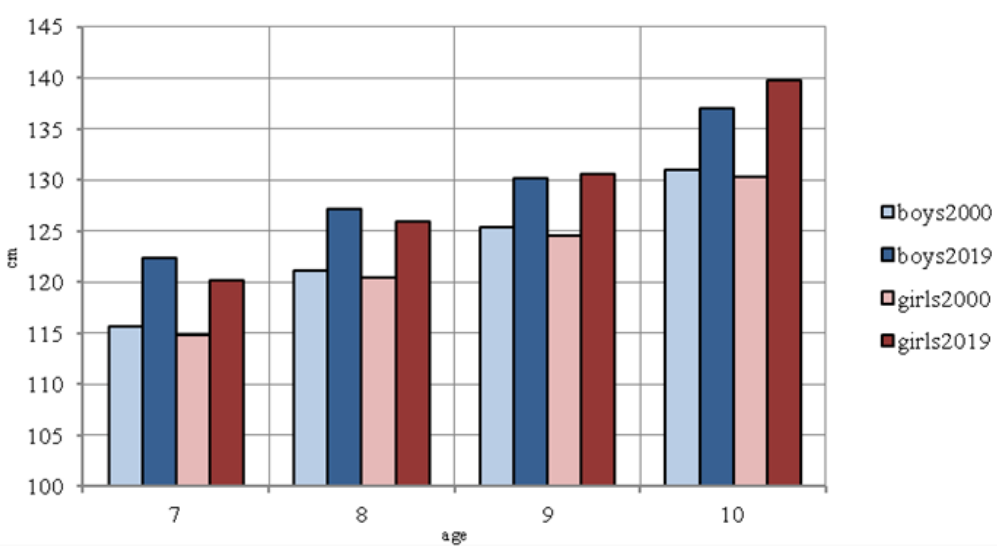

Graph 1: TV - the height of Romany boys and girls in both research cohorts

TH

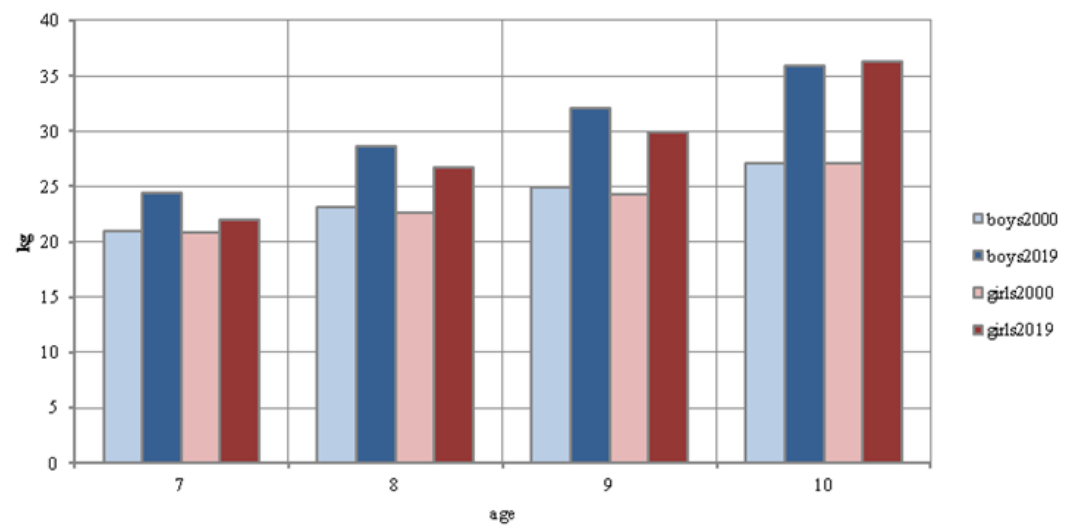

Graph 2: TH - the weight of Romany boys and girls in both research cohorts

An analysis of the two research projects has confirmed the HO 3 hypothesis according to which all age categories of Romany boys and girls have achieved better results in somatic parameters in the 2019 research than in the 2000 research. Horváth (2001) maintains that, in somatic parameters, Romany children fall behind the majority population by as much as two years. The 2019 results negate this claim. What is the reason for such a substantial improvement in somatic parameters? Is it a better standard of living of the Romany ethnic group? Our analysis of the measured values must take into consideration the heterogeneity of Romany communities. Any diagnosis of somatic parameters in Romany children must take into account the proportion of children living in settlements, villages and towns. Future research must reflect this fact and extend the number of tested children in order to obtain more reliable results. Diagram3 presents the BMI results for all age categories of boys and girls in both of these research projects. The BMI data give support to the $\mathrm{H} 0-4$ hypothesis saying that the results of the 2019 children are better than those presented in Horváth (2001). While the 2000 BMI data approach malnutrition, the 2019 BMI values meet the standard values for the given age category.

BMII

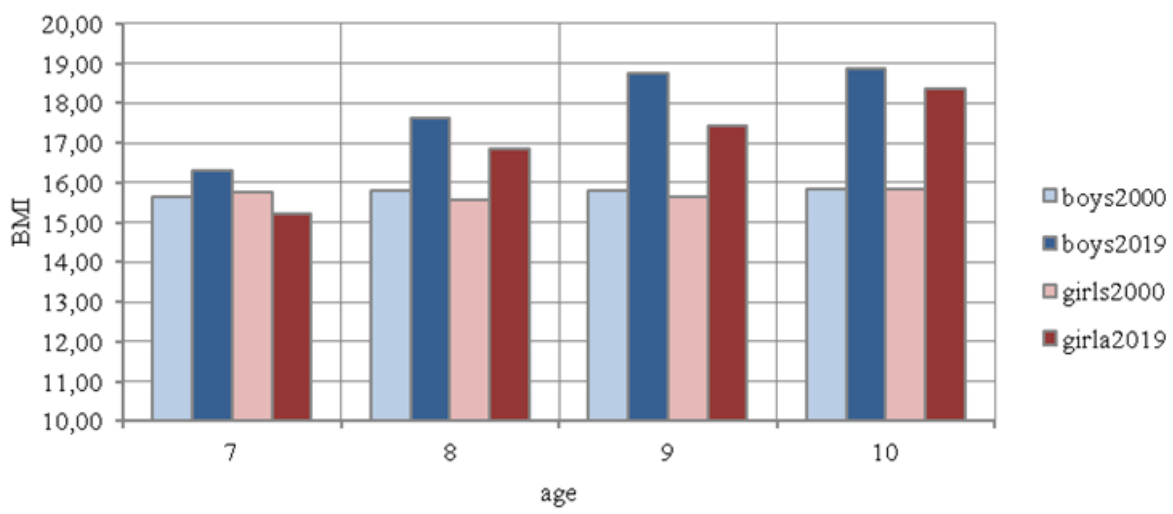

Graph 3: BMI - Body mass index of Romany boys and girls in both cohorts 
Tab. 3: Motion performance of 7- and 8-year-old Romany boys and girls

\begin{tabular}{|c|c|c|c|c|c|c|c|c|c|c|c|c|c|c|}
\hline & \multirow{2}{*}{\multicolumn{2}{|c|}{ age }} & \multicolumn{6}{|c|}{7} & \multicolumn{6}{|c|}{8} \\
\hline & & & $n$ & $\mathrm{x}$ & S & t & tkrit & t test & $n$ & $\mathrm{x}$ & $\mathrm{S}$ & t & tkrit & t test \\
\hline \multirow{4}{*}{ TR } & \multirow{2}{*}{ boys } & 2000 & 135 & 16.71 & 06.7 & \multirow{2}{*}{09.11} & \multirow{2}{*}{1.993} & \multirow{2}{*}{$* *$} & 142 & 14.76 & 7.31 & \multirow{2}{*}{8.54} & \multirow{2}{*}{1.99} & \multirow{2}{*}{$* *$} \\
\hline & & 2019 & 72 & 13.87 & 4.55 & & & & 74 & 10.94 & 4.64 & & & \\
\hline & \multirow{2}{*}{ girls } & 2000 & 136 & 16.74 & 6.73 & \multirow{2}{*}{8.44} & \multirow{2}{*}{1.99} & \multirow{2}{*}{$* *$} & 132 & 15.81 & 13.24 & \multirow{2}{*}{5.56} & \multirow{2}{*}{1.98} & \multirow{2}{*}{$* *$} \\
\hline & & 2019 & 74 & 12.8 & 04.1 & & & & 87 & 12.19 & 06.7 & & & \\
\hline \multirow{4}{*}{ TAP } & \multirow{2}{*}{ boys } & 2000 & 135 & 28.31 & 05.1 & \multirow{2}{*}{05.3} & \multirow{2}{*}{1.99} & \multirow{2}{*}{$* *$} & 142 & 27.51 & 6.33 & \multirow{2}{*}{9.22} & \multirow{2}{*}{1.99} & \multirow{2}{*}{$* *$} \\
\hline & & 2019 & 72 & 25.64 & 6.53 & & & & 74 & 21.72 & 5.34 & & & \\
\hline & \multirow{2}{*}{ girls } & 2000 & 136 & 32.12 & 5.47 & \multirow{2}{*}{9.26} & \multirow{2}{*}{1.99} & 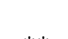 & 132 & 29.25 & 05.3 & & & 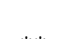 \\
\hline & & 2019 & 74 & 26.23 & 5.49 & & & & 87 & 21.19 & 05.4 & & & \\
\hline & & 2000 & 135 & 94.46 & 19.2 & & & & 142 & 106.34 & 17.61 & & & \\
\hline & ougs & 2019 & 72 & 103.13 & 20.7 & $4.0 \mathrm{~J}$ & 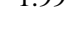 & & 74 & 116.3 & 16.83 & S & 1.93 & \\
\hline & & 2000 & 136 & 81.5 & 17.1 & & & & 132 & 95.99 & 16.59 & & & \\
\hline & gills & 2019 & 74 & 76.31 & 18.95 & 2.35 & 1.99 & & 87 & 102.55 & 17.62 & 3.49 & 1.99 & \\
\hline & & 2000 & 135 & 10.17 & 4.29 & & & & 142 & 12.25 & 4.49 & & & . \\
\hline & Doys & 2019 & 72 & 09.6 & 4.25 & 1.14 & 1.99 & 1.14 & 74 & 16.24 & 3.87 & 0.01 & 1.99 & \\
\hline & & 2000 & 136 & 7.54 & 3.93 & & & & 132 & 9.17 & 4.72 & & & \\
\hline & हा115 & 2019 & 74 & 7.61 & 2.95 & 0.21 & 1.99 & 0.21 & 87 & 14.28 & 3.91 & 12.2 & 1.99 & \\
\hline & & 2000 & 135 & 39.21 & 5.89 & & & & 142 & 28.99 & 5.85 & & & \\
\hline & & 2019 & 72 & 25.75 & 5.49 & 0.47 & 1.75 & & 74 & 25.32 & 03.5 & 04.9 & 1.99 & \\
\hline & & 2000 & 136 & 39.21 & 4.64 & & & 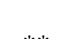 & 132 & 30.68 & 6.71 & & & 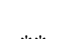 \\
\hline & gills & 2019 & 74 & 29.66 & 6.47 & & & & 87 & 25.35 & 3.62 & 15.15 & 1.97 & \\
\hline & & 2000 & 135 & 11.48 & 4.57 & & & & 142 & 17.31 & 11.54 & & & \\
\hline & & 2019 & 72 & 13.39 & 5.24 & & & & 74 & 14.14 & 5.53 & & & \\
\hline & & 2000 & 136 & 11.48 & 3.19 & & & & 132 & 13.1 & 4.55 & & & \\
\hline & & 2019 & 74 & 10.71 & 4.48 & 1.40 & 1. & 1.40 & 87 & 13.81 & 05.2 & 1.49 & 1.99 & \\
\hline
\end{tabular}

Tab. 4: Motion performance of 9-and10-year-old Romany boys and girls

\begin{tabular}{|c|c|c|c|c|c|c|c|c|c|c|c|c|c|c|}
\hline \multicolumn{3}{|c|}{ age } & \multicolumn{6}{|c|}{9} & \multicolumn{6}{|c|}{10} \\
\hline & & & $\mathrm{n}$ & $\mathrm{x}$ & $\mathrm{s}$ & $\mathrm{t}$ & tkrit & $\mathrm{t}$ test & $\mathrm{n}$ & $\mathrm{x}$ & $\mathrm{s}$ & $\mathrm{t}$ & tkrit & $\mathrm{t}$ test \\
\hline \multirow{4}{*}{ TR } & \multirow{2}{*}{ boys } & 2000 & 141 & 08.9 & 06.9 & \multirow{2}{*}{01.2} & \multirow{2}{*}{1.99} & \multirow{2}{*}{01.2} & 132 & 12.54 & 6.56 & \multirow{2}{*}{6.17} & \multirow{2}{*}{1.99} & \multirow{2}{*}{$* *$} \\
\hline & & 2019 & 72 & 9.44 & 4.47 & & & & 72 & 9.35 & 4.47 & & & \\
\hline & \multirow{2}{*}{ girls } & 2000 & 131 & 13.76 & 7.39 & \multirow{2}{*}{06.1} & \multirow{2}{*}{1.99} & \multirow{2}{*}{$* *$} & 141 & 12.54 & 06.3 & \multirow{2}{*}{09.11} & \multirow{2}{*}{1.99} & \multirow{2}{*}{$* *$} \\
\hline & & 2019 & 74 & 9.37 & 06.7 & & & & 77 & 8.26 & 04.9 & & & \\
\hline \multirow{4}{*}{ TAP } & \multirow{2}{*}{ boys } & 2000 & 141 & 27.67 & 6.98 & \multirow{2}{*}{12.88} & \multirow{2}{*}{1.99} & \multirow{2}{*}{$* *$} & 132 & 24.75 & 4.87 & \multirow{2}{*}{10.28} & \multirow{2}{*}{1.99} & \multirow{2}{*}{$* *$} \\
\hline & & 2019 & 72 & 21 & 4.36 & & & & 72 & 19.64 & 4.19 & & & \\
\hline & \multirow{2}{*}{ girls } & 2000 & 131 & 28.18 & 5.86 & \multirow{2}{*}{16.71} & \multirow{2}{*}{1.99} & \multirow{2}{*}{$* *$} & 141 & 24.75 & 05.11 & \multirow{2}{*}{9.72} & \multirow{2}{*}{1.99} & \multirow{2}{*}{$* *$} \\
\hline & & 2019 & 74 & 20.31 & 04.1 & & & & 77 & 19.97 & 4.29 & & & \\
\hline & & 2000 & 141 & 18.89 & 4.98 & & & & 132 & 18.78 & 4.25 & & & \\
\hline & ouys & 2019 & 72 & 17.13 & 7.95 & 1.00 & 1.99 & 1.00 & 72 & 15.14 & 8.82 & 5.41 & 1.99 & \\
\hline & & 2000 & 131 & 18.12 & 4.32 & & & & 141 & 18.78 & 04.5 & & & \\
\hline & & 2019 & 74 & 15.35 & 7.97 & & & & 77 & 15.39 & 08.12 & 3.64 & 1.99 & \\
\hline & & 2000 & 141 & 108.34 & 22.44 & & & & 132 & 108.51 & 19.84 & & & \\
\hline SKOK & $00 y^{\circ}$ & 2019 & 72 & 107.6 & 16.5 & & & & 72 & 117.06 & 18.34 & 2 & & \\
\hline & girls & 2000 & 131 & 97.75 & 15.31 & 2.98 & 1.99 & $* *$ & 141 & 108.51 & 16.9 & 1.49 & 1.99 & $* *$ \\
\hline
\end{tabular}




\begin{tabular}{|c|c|c|c|c|c|c|c|c|c|c|c|c|c|c|}
\hline & & 2019 & 74 & 97.65 & 17.27 & & & & 77 & 105.51 & 20.25 & & & \\
\hline \multirow{4}{*}{ LS } & \multirow{2}{*}{ boys } & 2000 & 141 & 14.21 & 04.9 & \multirow{2}{*}{4.49} & \multirow{2}{*}{1.99} & \multirow{2}{*}{$* *$} & 132 & 12.13 & 4.74 & \multirow{2}{*}{13.27} & \multirow{2}{*}{1.99} & \multirow{2}{*}{$* *$} \\
\hline & & 2019 & 72 & 16.56 & 4.39 & & & & 72 & 18.65 & 4.14 & & & \\
\hline & \multirow{2}{*}{ girls } & 2000 & 131 & 11.69 & 4.86 & \multirow{2}{*}{5.41} & \multirow{2}{*}{1.99} & \multirow{2}{*}{$* *$} & 141 & 12.13 & 4.46 & \multirow{2}{*}{8.85} & \multirow{2}{*}{1.99} & \multirow{2}{*}{$* *$} \\
\hline & & 2019 & 74 & 14.38 & 4.24 & & & & 77 & 16.57 & 4.36 & & & \\
\hline \multirow{4}{*}{ VZH } & \multirow{2}{*}{ boys } & 2000 & 141 & 13.84 & 10.9 & \multirow{2}{*}{0.07} & \multirow{2}{*}{1.99} & & 132 & 8.67 & 06.5 & \multirow{2}{*}{7.93} & \multirow{2}{*}{1.99} & \multirow{2}{*}{$* *$} \\
\hline & & 2019 & 72 & 13.91 & 8.16 & & & & 72 & 19.15 & 11.13 & & & \\
\hline & \multirow{2}{*}{ girls } & 2000 & 131 & 7.76 & 4.64 & \multirow{2}{*}{0.35} & \multirow{2}{*}{1.99} & & 141 & 8.67 & 5.66 & \multirow{2}{*}{2.95} & \multirow{2}{*}{7.99} & \multirow{2}{*}{$* *$} \\
\hline & & 2019 & 74 & 7.55 & 4.94 & & & & 77 & 11.79 & 9.21 & & & \\
\hline \multirow{4}{*}{$\mathrm{CBEH}$} & \multirow{2}{*}{ boys } & 2000 & 141 & 27.35 & 06.12 & \multirow{2}{*}{7.47} & \multirow{2}{*}{1.99} & \multirow{2}{*}{$* *$} & 132 & 28.83 & 05.12 & 177 & 100 & $* *$ \\
\hline & & 2019 & 72 & 23.85 & 3.95 & & & & 72 & 22.22 & 3.15 & 11.11 & 1.99 & \\
\hline & girls & 2000 & 131 & 29.74 & 5.77 & 010 & 199 & $* *$ & 141 & 28.83 & 5.79 & 1380 & 199 & $* *$ \\
\hline & $8+1$ & 2019 & 74 & 25.79 & 3.76 & . & & & 77 & 24.52 & 2.71 & & 列 & \\
\hline & boure & 2000 & 141 & 18.97 & 7.28 & 357 & 100 & $* *$ & 132 & 18.17 & 7.19 & 08 & 100 & 08 \\
\hline & (5) & 2019 & 72 & 16.64 & 05.5 & 1. & 政 & & 72 & 17.5 & 6.98 & 0.0 & $1.7 \%$ & 0.0 \\
\hline & oirls & 2000 & 131 & 14.57 & 5.37 & 086 & 199 & 086 & 141 & 18.17 & 6.31 & 371 & 199 & $* *$ \\
\hline & हा15 & 2019 & 74 & 14.23 & 3.37 & 0.00 & 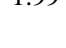 & 0.00 & 77 & 16.13 & 4.79 & 3.11 & (1.) & \\
\hline
\end{tabular}

The EUROFIT test was used to test motion performance. The measured values were used to calculate the basic statistical variables, i.e., the arithmetic average and the standard deviation. The results of Horváth (2001) were compared to the present data for each age category of Romany boys and girls with regard to each test item in order to verify the hypotheses. This was performed by means of the one sample t-test. We specified the statistical significance of the identified differences. The values are given in Tables 3 and 4 .

item separately for boys and girls and for each age category.

Our analysis of the TR, TAP, SKOK a CBEH item tests indicates statistical significance at the level of 0.05 for all the differences between the compared cohorts (Horváth 2001 and
When analyzing the basic statistical items we decided to exclude the test items PRKL - sit and reach, and VZH - push-up test, because the coefficient of variation, i.e., the proportion between the standard deviation and the arithmetic average exceeds $50 \%$. This means that the arithmetic average and the standard deviation in these two test items are not sufficiently valid for subsequent processing. Turek (1999) arrived at a similar conclusion in similar research which, however, was focused on the majority population in East Slovakia. Since the t-test was the 2019 tests) and for all age categories of boys and girls. Consequently, we reject the $\mathrm{H} 0-2$ null hypothesis and confirm the alternative $\mathrm{H} 1-2$ hypothesis. All in all, statistically significant differences between the two cohorts have been confirmed for these test items.

TR

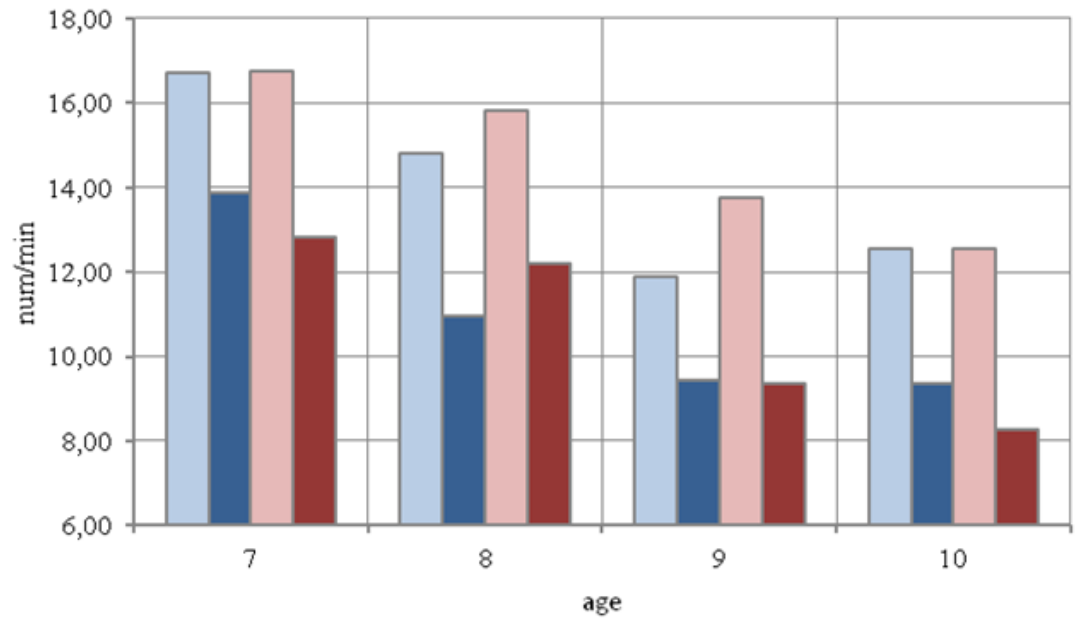

口boys 2000

mboys 2019

口girls2000

mirls2019

Graph 4: Comparison of the TR test item values - Flamingo balance test

It follows from Graph 4 that the most significant improvement was achieved for 8-year-old boys and 9-year-old girls. In general, the H0-4 null hypothesis has been confirmed for the TR item, according to which the Romany children of 2019 tests achieve better results for all age categories of boys and girls than the Romany children tested in 2000. 
TAP - plate tapping - factor: frequency speed of hand

TAP

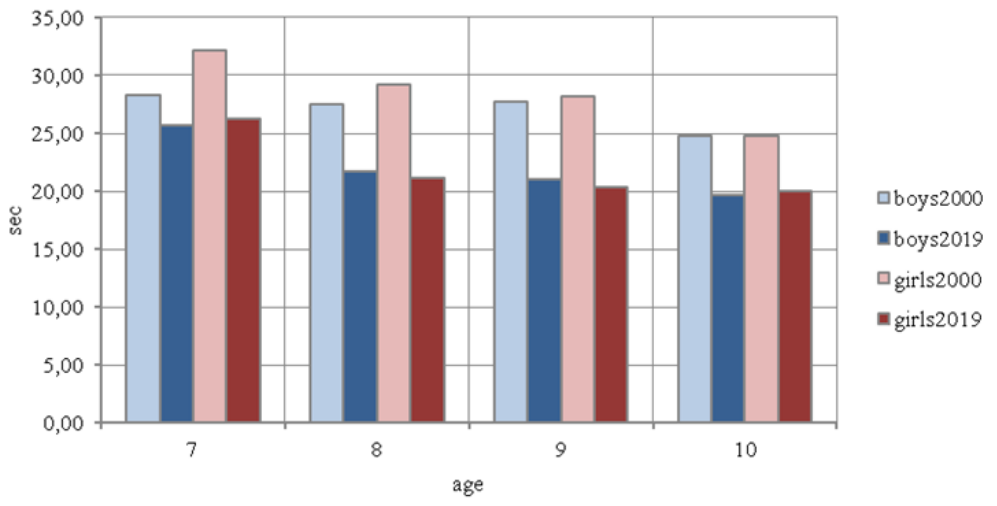

Graph 5: Comparison of the TAP test item values - plate tapping
It follows from graph 5 that the 2019 cohort's results are better than those of the 2000 cohort for all age categories. The most striking difference occurs in the groups of 8-year-old boys and 9year-old girls. In general, the $\mathrm{H} 0-4$ hypothesis has been

SKOK - standing long jump - dynamic strength of legs confirmed for all age categories of both genders. This means that the 2019 cohort achieved better results than the cohort presented in Horváth (2001).

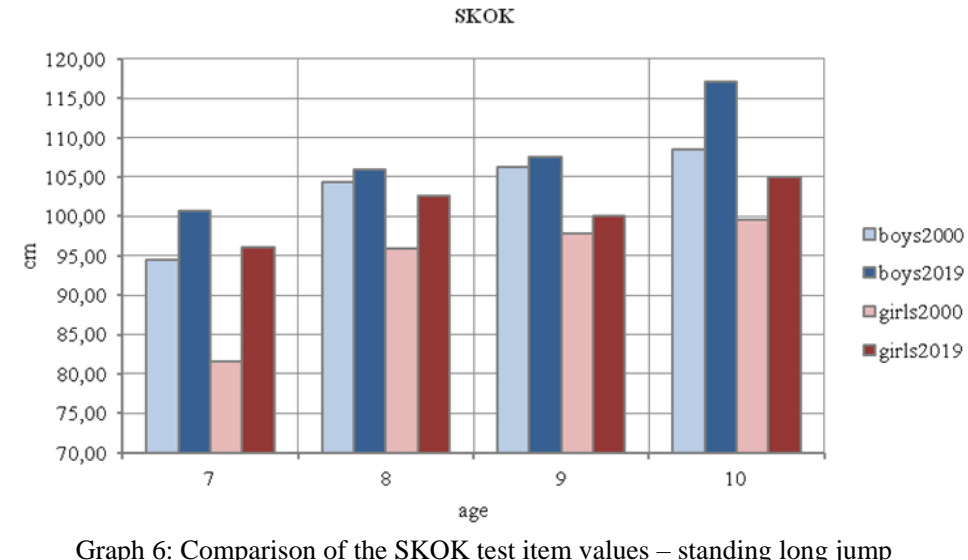

Better results of the 2019 cohort compared to the 2000 cohort, including all age categories of both genders, also apply to the SKOK item. The biggest difference has been identified for the groups of 10-year-old boys and girls. The H0-4 hypothesis has been unambiguously confirmed. In sum, the results of Romany boys and girls tested in 2019 are better than those discussed in Horváth (2001).

$\mathrm{CBEH}$ - shuttle run $10 \times 5 \mathrm{~m}$ - running velocity with direction changes

CBEH

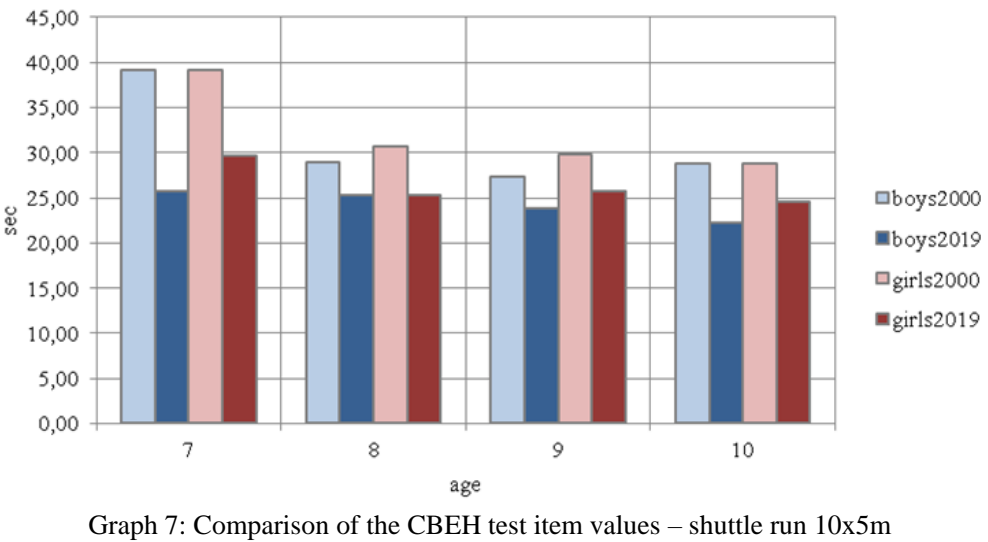


The H0-4 hypothesis has been confirmed for the CBEH test item, too: the results of the Romany boys and girls tested in 2019 are better than the results presented in Horváth (2001).

LS - sit-ups - dynamic and endurance strength of the abdominal and loins-thigh muscles

As it follows from Tab. 3 and 4, this test item does not unambiguously confirm the $\mathrm{H} 0-2$ hypothesis for all age categories of boys and girls. The Ho-1 has been confirmed for the groups of 7-year-old boys and girls, i.e., there are no statistically significant differences between the two compared cohorts.

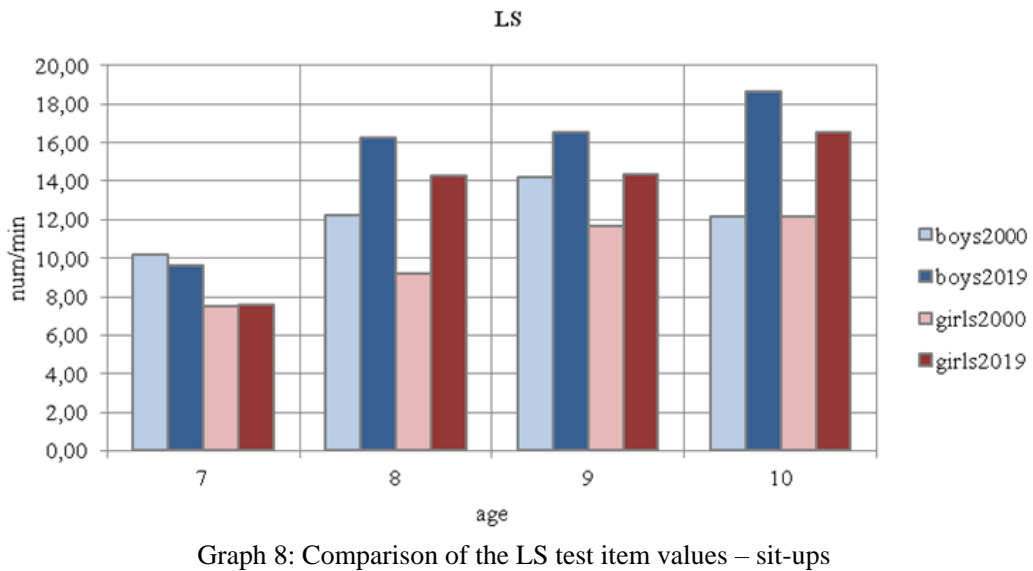

Graph 8 indicates that the H0-4 hypothesis has not been confirmed for the groups of 7-year-old boys and girls. The results of the 2019 cohort for this age group are not better than those of the 2000 cohort. However, this hypothesis has been confirmed for all the other age categories. The alternative H1-2 hypothesis, according to which there are statistically significant

VBEH - multistage shuttle run - running endurance

Tables 3 and 4 clearly show that the VBEH test item multistage shuttle run - is the most ambiguous of all test items. The H1-2 hypothesis has been confirmed for the category of 7-, differences between the 2000 and the 2019 cohorts, has been confirmed for the age categories of 8-, 9- and 10-year-old boys and girls. In addition, the hypothesis $\mathrm{H} 0-4$ has been confirmed for the age categories of 8-, 9- and 10-year-old children, i.e., the results of the 2019 cohort are better than those of the 2000 cohort.
8- and 9-year-old boys and the category of 10-year-old girls. In these cases, the differences between the results of the two compared cohorts are statistically significant.

VBEH

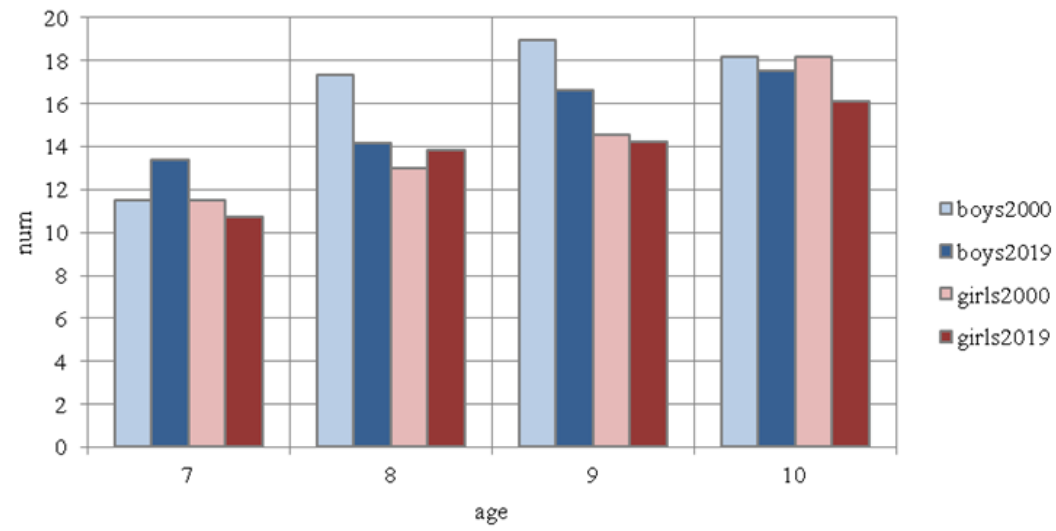

Graph 9: Comparison of the VBEH test item values - multistage shuttle run

Graph 9 shows that the H0-4 hypothesis has been confirmed only in the category of 7-year-old boys and 8-year-old girls: the results of the 2019 cohort are better than those of the 2000 cohort only in these groups of Romany children. The age

\section{Conclusion}

Research covering 596 Romany children at the age of primary school has brought the following observations and findings:

1. Somatic parameter tests have confirmed the H1 1 hypothesis, according to which there are statistically significant differences in somatic parameters between the categories of 8-, 9- and 10-year old boys and 7-, 9- and 10-year old girls tested in 2000 have better results than their counterparts in 2019, even though these differences are not statistically significant in every single case.

cohort reported in Horváth (2001) and the 2019 cohort. This hypothesis has been confirmed for all age categories of boys and girls.

2. The 2019 cohort features statistically significant advantage against the 2000 cohort. While the 2000 cohort fell behind the majority population in somatic parameters by as much as 
two years, the 2019 data do not show this kind of differences. Do the reasons for this change stem from a higher standard of living of Romany children and better socialization of Romany population, especially in towns? This question is still to be answered in future research.

3. The motion performance was tested by a modified EUROFIT test. Due to the insufficiently valid results, the test items PRKL - sit and reach, and VZH - push-up test, were excluded from subsequent evaluation. The results of the other items can be divided into two groups:

a. Test items TR, TAP, SKOK and VBEH fall within the hypothesis H1-2, i.e., there are statistically significant differences between the results of the Romany children in Horváth (2001) and the results of the Romany children in the 2019 research. Our analysis has confirmed the H0-3 hypothesis for these items saying that the results of Romany children tested in 2019 are better than the results of the cohort reported in Horváth (2001) in a statistically significant way.

b. The testing of hypotheses for test items LS and VBEH has been ambiguous for all age categories of boys and girls.

The results of the motion performance coincide in the majority of cases with the results obtained for somatic parameters.

A comparison of the results of Romany children must take into consideration the fact that they live in three substantially different environments:

- Romany children who live in towns and regularly attend school

- Romany children who live in villages and are relatively well socialized with the village population

- Romany children who live in settlements

Future research should:

Focus on a balanced composition of a sample of Romany children in terms of the three above-mentioned groups;

Increase the number of tested Romany children in order to avoid statistical errors due to a small number of tested children.

\section{Literature:}

1. Horváth R.: Telesný vývin a pohybová výkonnost' rómskych detí mladšieho školského veku, ManaCon Prešov, 2001, 135p. ISBN 80-89040-08-X

2. Moravec R. et al: EUROFIT: Telesný rozvoj a pohybová výkonnost' školskej populácie na Slovensku, VSTVŠ Bratislava, 1996, 181p. ISBN 80-967487-1-8

3. Turek M.: Telesný vývin a pohybová výkonnost' detí mladšieho školského veku, Slovenská vedecká spoločnost' pre telesnú výchovu a šport, Východoslovenská pobočka Prešov, 1999, 110p. ISBN 80-88885-61-2

\section{Primary paper section: A}

Secondary paper section: AM 